\title{
The Integrative Effects of Flexible Work Arrangements and Preferences for Segmenting or Integrating Work and Home Roles
}

\author{
MaryAnne M. Hyland \\ Adelphi University \\ Ciaran Rowsome \\ Flextime Limited \\ Erin Rowsome \\ The University of Dublin, Trinity College
}

\begin{abstract}
Flexible work arrangements are being offered by an increasing number of organizations for recruitment and retention purposes. However, Person-Environment Fit theory (Edwards, 1996) suggests that flexible work arrangements may not be beneficial for all employees. This study examined the relationship of flexible work arrangement use with employee performance, affective commitment, and turnover intentions, while taking into consideration the moderating effects of employees' preferences for segmenting or integrating their work and home lives. The sample consisted of 172 employees from eight organizations in Ireland. Marginally significant effects for compressed workweeks were found. Implications for future practitioners and future research are discussed.
\end{abstract}

\section{Introduction}

Flexible work arrangements are intended to serve as a strategic tool to attract, retain, and motivate employees in the current business environment of increased competition and high demands on workers (Kropf, 1996; Olmsted \& Smith, 1997). Such arrangements have also been advocated as a means of aligning individual and organizational objectives (Apgar, 1998; Ronen, 1984). Anecdotal evidence suggests that there are work-related benefits of flexible work arrangements, such as increased productivity (e.g., Catalyst, 1997; Di Martino \& Wirth, 1990). However, although research dating back to the 1970 s has examined the work-related benefits of flexible work arrangements (e.g., Hicks \& Klimoski, 1981; Schein, Maurer, \& Novak, 1977), a clear body of evidence of such benefits has not emerged.

Recent theoretical development on the boundaries between work and family roles (e.g., Ashforth, Kreiner, \& Fugate, 2000; Clark, 2000, Nippert-Eng, 1996) may shed light upon the relationship between flexible work arrangements and work-related outcomes, such as employee performance, affective organizational commitment, and turnover intentions. Nippert-Eng's (1996) qualitative study explains what she refers to as "boundary theory" in the context of home and work. Based on extensive interviews and analysis, Nippert-Eng explains how individuals keep separate (segment) or intertwine (integrate) their work and home lives. For example, she provides examples of highly segmenting individuals who keep separate calendars for their work and home activities 
and who wear different clothes for their work and home roles. In contrast, she provides examples of individuals who combine work and home activities on one calendar and who wear the same type of clothes at home and work. Nippert-Eng (1996) proposes that segmentation and integration are opposite ends of a continuum. However, she suggests that most individuals combine segmenting and integrating practices, resulting in a more or less integrating/segmenting approach to work, rather than achieving the ideal type of segmentor or integrator (Nippert-Eng, 1996, p. 6). All types of flexible work arrangements allow for greater integration of work and home roles than the standard Monday through Friday "nine to five" forty hour work week. However, some flexible work arrangements allow for more integration than others. For example, when using flextime, an individual still may keep separate calendars for work and home activities, whereas a teleworker may benefit more from combining calendars since he/she may enter and exit the work and home roles several times each day. The present study examines whether preferences for integration or segmentation of work and home roles interact with the use of flexible work arrangements to affect work-related outcomes.

\section{Flexible Work Arrangements}

Flexible work arrangements allow for work to be accomplished outside of the traditional time and/or space boundaries of the standard workday. Although there is no truly "standard" day, in that hours and the location of work differ based on such categorizations as job type and organizational norms, a traditional work schedule is defined as a forty hour week, from 9:00 a.m. to 5:00 p.m., Monday through Friday (Catalyst, 1997). Flexible work arrangements allow work to be performed before or after standard working hours, as well as from alternative locations, such as an employee's home. Flextime, compressed work weeks, job sharing, and telework, are commonly accepted forms of flexible work arrangements (Duxbury \& Haines; 1991; Friedman, 1990; Morgan and Milliken, 1992).

The degree of flexibility to coordinate work and nonwork demands has been conceptualized as the key element in defining flexible work arrangements when relating flexible working arrangements to employee attitudes and behaviors (Pierce, Newstrom, Dunham, and Barber, 1989). This implies that the study of flexible work arrangements is more complex than simply examining whether or not an employee uses a flexible work arrangement. Rather, there may be varying degrees of flexibility that meet employee preferences or needs, which may ultimately affect outcomes of the arrangement for both the employer and the employee. Thus, unlike previous studies, the present research conceptualizes flexible work arrangements on a continuum, rather than as isolated dichotomous constructs that are either "used" or "not used". 
Figure 1. Work Arrangements on the Role Segmentation-Role Integration Continuum (adapted from Rau and Hyland, 2002).

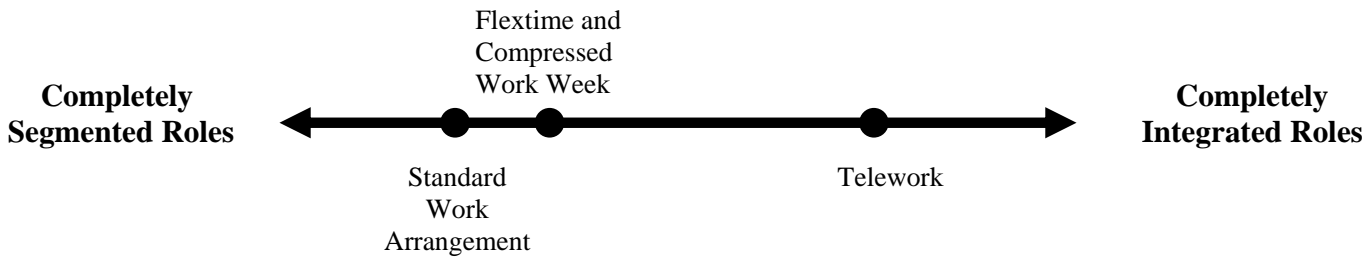

\section{Flextime}

The concept of flextime allows employees to vary their work schedules, within certain ranges and dimensions, according to their differing needs (Ronen, 1981). It focuses exclusively on the work schedule. Flextime does not affect the total number of working hours required or the location at which work is done. According to Rau and Hyland (2002), who compared flextime and telework to a standard work arrangement on a segmentation-integration continuum, flextime allows for slightly more integration of work and home life than does a standard work arrangement due to increased temporal flexibility in the boundaries between work and home. (See Figure 1.) For example, if a parent wanted to be home at 3:30 p.m. to meet his child after school, a standard work arrangement would not enable him to do so. However, using flextime, the parent could begin work at 7 a.m. and finish work at 3 p.m. in time to meet his child.

Research on the work-related outcomes of flextime has not found flextime to be unequivocally beneficial to organizations; however, most research suggests positive effects on business outcomes. A meta-analysis of flextime studies found that productivity increased when flextime was used; however, it did not find a significant main effect of flextime on self-rated employee performance (Baltes, Briggs, Huff, Wright, \& Neuman, 1999). Organizational commitment has been found to be positively related to the availability of flextime (Scandura \& Lankau, 1997) and turnover intentions have been found to be negatively related to the use of flextime (Golembiewski \& Proehl, 1978). Thus, some evidence for a positive effect of flextime on performance has been found.

\section{Compressed Work Week}

The compressed work week condenses the hours in the standard work week into fewer days (Ronen \& Primps, 1981). The total number of hours required per week or month usually remains the same. The rationale is similar to flextime in that it does not affect 
the number of hours required or the work location. However, with the compressed work week, there is no core time, which enables employees to work a greater number of hours on certain days and then not work at all on other days. For example, on a four day/40 hour schedule, an employee would work 10 hours per day for four days, and then not have to work on the fifth day of that week. Although Rau and Hyland (2002) did not include compressed work week arrangements on their proposed continuum, such arrangements are similar to flextime in that they only increase the temporal flexibility and do not affect the location of where the work is conducted. Therefore, like flextime, they should be slightly closer to the integration end of the segmentation-integration continuum than the standard work arrangement. (See Figure 1.)

Like the research for flextime, studies on compressed work weeks have found mixed results. Ronen and Primps' (1981) literature review found improvements in productivity and/or service for four of seven studies in which compressed workweeks were implemented, while the remaining studies reported no change. A more recent study also reported an increase in productivity (Vega \& Gilbert, 1997). Pierce and Dunham (1992) found no effect for compressed workweeks on organizational commitment; however, a research review did find positive effects of compressed work weeks on job-related attitudes like organizational commitment (Ronen \& Primps, 1981). Although I am unaware of a study that specifically examined the effects of compressed workweeks on turnover, Latack and Foster (1985) did find reductions in sick time and personal leave time as a result of implementing a compressed workweek schedule. Therefore, as with flextime, there is some evidence of work-related benefits associated with compressed workweeks.

\section{$\underline{\text { Telework }}$}

Telework includes employees who work from home or another remote site, such as a satellite office. The term is similar to "telecommuting", which is working from home, but it also includes working from such off-site locations as a hotel room or the local library. Rau and Hyland (2002) place telework furthest towards the integration end of the segmentation-integration continuum when compared to the standard work arrangement and flextime. (See Figure 1.) This is due to the likelihood of both temporal flexibility (determining when work is conducted) and spatial flexibility (conducting work from various remote locations) being permitted under a teleworking arrangement.

Increases in productivity were reported in a review of telecommuting studies (PittCatsouphes \& Marchetta, 1991) and in a recent natural experiment (Hill, Miller, Weiner, \& Colihan, 1998). However, using experimental design, Ramsower (1985) did not find effects of telecommuting on productivity. I was unable to find a study that examined the effect of telework on affective commitment; however, there are studies on turnover. One such survey found improved retention of professional staff was a significant benefit for firms offering telecommuting programs (Tomaskovic-Devey \& Risman, 1993). However, a statistically significant effect on turnover was not found by Ramsower (1985) in an experimental study. Thus, there is some evidence of reduced turnover being associated with telework. 


\section{$\underline{\text { Segmentation-Integration Preferences and Flexible Work Arrangements }}$}

The notion of preferring to segment work and home roles, rather than integrating them has been proposed as an area for future research (e.g., Ashforth, et al., 2000). Such preferences can be related to the use of flexible work arrangements, as individuals who prefer integrating their work and home roles may benefit most from a work arrangement that allows them a greater degree of integration. Kreiner (2002) uses a personenvironment (P-E) fit perspective to examine the effects of individual preferences for segmentation and integration and what he refers to as "workplace supplies" on workfamily conflict, stress, and job satisfaction. The concept of P-E fit suggests that attitudes, behavior, and other individual-level outcomes result from the relationship between the person and his/her environment, rather than from either of the two separately (Edwards, 1996). Although Kreiner's workplace supplies are a general aspect of the environment, rather than relating specifically to flexible work arrangements, they tap into concepts related to segmentation that are associated with flexible work arrangements (e.g., "My workplace lets people forget about work when they're at home").

The present study uses a P-E fit perspective similar to that proposed by Kreiner (2002). However, this research examines the fit between segmentation-integration preferences and flexible work arrangements. Based on the P-E fit perspective, preferences for segmenting work and home life (a personal characteristic) combine with the environmental feature of being able to use a flexible work arrangement to affect individual-level work outcomes. A model of the proposed relationships is depicted in Figure 2.

Figure 2. Proposed Model

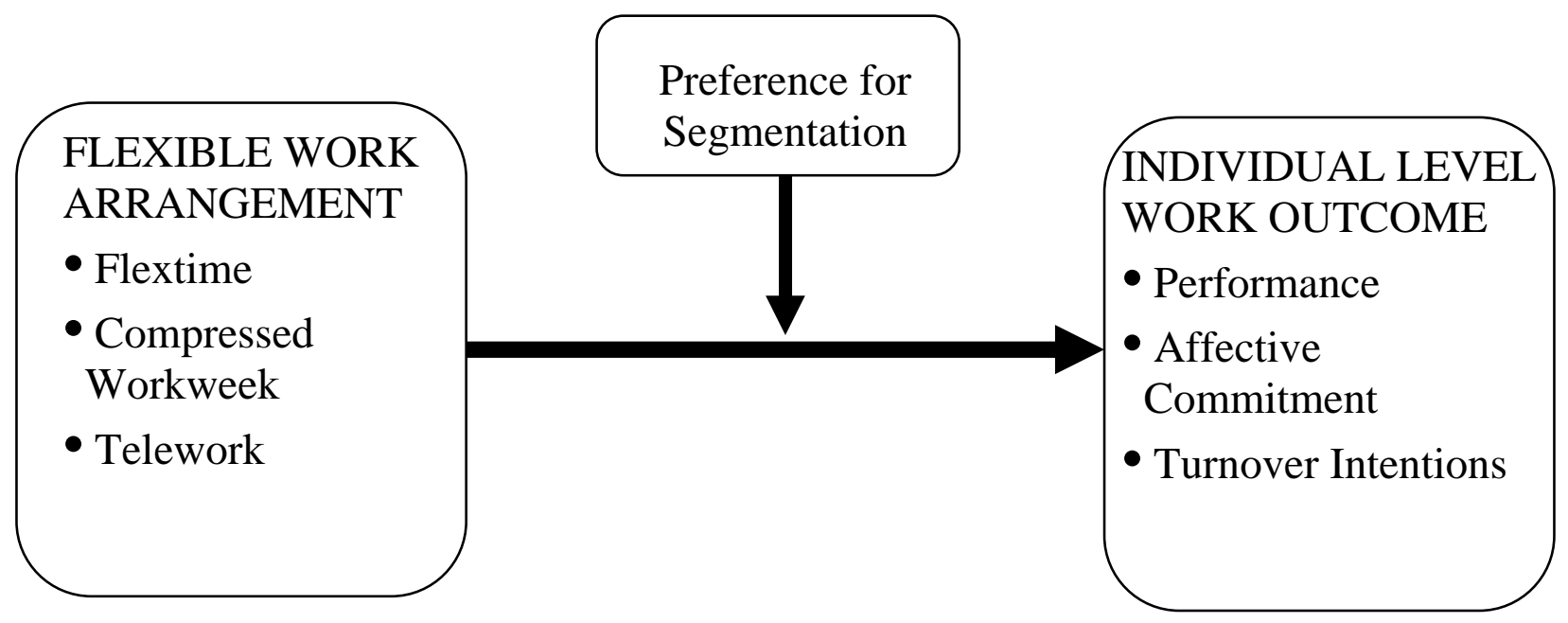


Of all the flexible work arrangements previously listed, flextime is the most similar to a standard work arrangement in the level of segmentation that it permits. Work and home life are kept separate while an individual is fulfilling one of these roles, yet the timing under which an individual can enact the role is flexible. Thus, an individual whose needs are met with merely a schedule change is likely to be attracted to a flextime arrangement. Likewise, P-E fit theory suggests that individuals who prefer segmentation will "fit" well with using a flextime arrangement. This should result in positive effects on performance and affective commitment, and negative effects on turnover when individuals with a high preference for segmentation use flextime.

Given that most of the research on flextime suggests beneficial effects on work-related outcomes, the hypotheses propose a positive main effect, and then a moderated relationship of flexible work arrangements and preference for segmentation on these work-related outcomes:

Hypothesis 1a: The relationship between flextime and individual performance will be positive, with a strong positive effect for individuals with a high preference for segmentation (low preference for integration) and with a weak positive effect for individuals with a low preference for segmentation.

Hypothesis 1b: The relationship between flextime and affective commitment will be positive, with a strong positive effect for individuals with a high preference for segmentation (low preference for integration) and with a weak positive effect for individuals with a low preference for segmentation.

Hypothesis 1c: The relationship between flextime and turnover intentions will be negative, with a strong negative effect for individuals with a high preference for segmentation (low preference for integration) and with a weak negative effect for individuals with a low preference for segmentation.

A compressed work week allows for flexibility in the timing of work, much like flextime, except that compressed workweeks vary the hours worked each day in order to reduce the number of days worked per week. Still, when an individual is working, his work life is kept separate from his personal life. Thus, an individual whose needs are met with a schedule change that reduces the number of days worked each week is likely to be attracted to and effective working under a compressed work week arrangement. As with flextime, P-E fit theory suggests that individuals who prefer segmentation will "fit" well with using a compressed workweek arrangement.

Hypothesis 2a: The relationship between compressed workweek and individual performance will be positive, with a strong positive effect for individuals with a high preference for segmentation (low preference for integration) and with a weak positive effect for individuals with a low preference for segmentation.

Hypothesis 2b: The relationship between compressed workweek and affective commitment will be positive, with a strong positive effect for individuals with a high 
preference for segmentation (low preference for integration) and with a weak positive effect for individuals with a low preference for segmentation.

Hypothesis 2c: The relationship between compressed workweeks and turnover intentions will be negative, with a strong negative effect for individuals with a high preference for segmentation (low preference for integration) and with a weak negative effect for individuals with a low preference for segmentation.

Unlike flextime and the compressed work week, telework allows for deviations from the standard work arrangement in terms of both the timing and the location of work. Thus, telework falls closer to the integration end of the continuum. Following the P-E fit perspective, individuals with a low preference for segmentation (high preference for integration) will be most attracted to and most effective working under a telework arrangement.

Hypothesis 3a: The relationship between telework and performance will be positive, with a weak positive effect for individuals with a high preference for segmentation (low preference for integration) and with a strong positive effect for individuals with a low preference for segmentation.

Hypothesis 3b: The relationship between telework and affective commitment will be positive, with a weak positive effect for individuals with a high preference for segmentation (low preference for integration) and with a strong positive effect for individuals with a low preference for segmentation.

Hypothesis 3c: The relationship between telework and turnover intentions will be negative, with a weak negative effect for individuals with a high preference for segmentation (low preference for integration) and with a strong negative effect for individuals with a low preference for segmentation.

\section{Method}

\section{Sample}

Participants were 172 employees from eight organizations in Ireland. The organizations were both public and private. Most were small organizations or a division of a larger organization, such as a university. Of the participants, $76 \%$ were female, $35 \%$ arrange for the care of at least one child, and $53 \%$ had a spouse or partner who works outside of the home. The average age of the participants was 38 years. Forty-seven percent of the participants classified their job level as clerical or support; eight percent as semiprofessionals; $26 \%$ as professionals or supervisors; and $16 \%$ as mid-level to upper management (three percent gave no response to this question).

\section{Procedures}


The participating organizations were contacted by one of the researchers regarding the study. The researcher explained that the study would consist of an anonymous questionnaire that would be distributed to the employees at their work address and would be returned directly to the researcher. Each participant received a packet containing a letter from the principal researchers, a consent form, and a questionnaire. One of the researchers went to each site to collect the completed questionnaires.

\section{$\underline{\text { Measures }}$}

Employee Performance. Individual employee performance was measured with a scale developed by Tsui, Pearce, Porter, \& Tripoli (1997), with items added from Greenhaus, Parasuraman, and Wormley (1990). This scale was chosen due to its focus on core tasks, rather than citizenship behavior that may fall beyond basic task performance. For the current study, the 5-point response scale for the first five items ranged from $1=$ strongly disagree to $5=$ strongly agree. The four items from Greenhaus et al. (1990) used a response format ranging from $1=$ unsatisfactory to $5=$ excellent. The overall eleven item scale was found to have an inter-item reliability of .89 .

Turnover Intentions. Four items used by Wayne, Shore, and Liden (1997) measured turnover intentions. Responses to each item were made on a 5-point Likert type scale ( $1=$ strongly disagree, $5=$ strongly agree). The inter-item reliability for this scale was .91 .

Affective organizational commitment. Affective organizational commitment was measured using Meyer, Allen, \& Smith's (1993) six item scale. For the current study, responses to each item were made on a 5-point Likert type scale (1=strongly disagree, $5=$ strongly agree). The inter-item reliability for this scale was .82 .

Flextime. Use of flextime was measured with a single item which read, "Are you currently using flextime? (an arrangement by which you can come to work and leave at times other than the official start and end of the work day, without changing the total number of hours worked from that of a standard work day)". Responses were made on a 6 -point Likert scale ( $1=$ not at all, $2=$ occasionally, $3=$ less than $50 \%$ of the time, $4=$ more than $50 \%$ of the time, $5=$ most of the time, $6=$ all of the time).

Compressed work week. Use of a compressed work week was measured by a single item which read, "Are you currently using a compressed work week? (an arrangement by which you come to work fewer than five days per week, without reducing the total number of hours worked from that of a standard five day work week)". Responses were made on a 6 -point Likert scale (1= not at all, $2=$ occasionally, $3=$ less than $50 \%$ of the time, $4=$ more than $50 \%$ of the time, $5=$ most of the time, $6=$ all of the time).

Telework. Use of telework was measured using a single item which read, "Are you currently using teleworking? (an arrangement by which you work from a location other than the standard work location. For example working from home or the local library)". Responses were made on a 6 -point Likert scale (1= not at all, 2=occasionally, $3=$ less 
than $50 \%$ of the time, $4=$ more than $50 \%$ of the time, $5=$ most of the time, $6=$ all of the time).

Segmentation Preferences. Segmentation preferences were measured using Kreiner's (2002) four item scale ("I don't like to have to think about work while I'm at home"; "I prefer to keep work life at work"; "I don't like work issues creeping into my home life"; "I like to be able to leave work behind when I go home"). Responses were indicated on a 5 -point Likert scale (1=strongly disagree, $5=$ strongly agree). The inter-item reliability for this scale was .78 .

\section{$\underline{\text { Analysis }}$}

Three sets of hierarchical ordinary least squares regression was used to test the hypotheses. Gender, making childcare arrangements, and having a working spouse all were considered as control variables. Preliminary analyses showed that only working spouse had an association with any of the dependent variables. Therefore, working spouse was the only control variable included in the regression models. The three regression models were the same except for the dependent variable. In the first regression model, employee performance was the dependent variable. In the second model, turnover intentions were the dependent variable. In the third model, affective commitment was the dependent variable. For all three models, in the first step of the hierarchical regression analysis, the dependent variable was regressed on the control variable and the three flexible work arrangements. In the second step, the main effect for segmentation preferences was added. In the third step, the interactions between segmentation preferences and the various flexible work arrangements were added. 


\section{Results}

Descriptive statistics and intercorrelations for the primary variables in the study are presented in Table 1. Flextime was the only flexible work arrangement to show a significant relationship with any of the work-related outcomes. Interestingly, the effects were not beneficial, as flextime was positively correlated with turnover intentions and negatively correlated with affective commitment. Figure 3 shows a frequency distribution for segmentation preferences. Although the responses are positively skewed, there is variance, which suggests that individuals do indeed differ in their preferences for segmenting and integrating work and family roles. 
Table 1. Descriptive Statistics and Intercorrelations Among Variables $(n=153)$

\begin{tabular}{|c|c|c|c|c|c|c|c|c|c|}
\hline Variable & $\mathrm{M}$ & SD & 1. & 2. & 3. & 4. & 5. & 6. & 7. \\
\hline $\begin{array}{l}1 . \\
\text { Employee } \\
\text { Performanc } \\
\text { e }\end{array}$ & 3.88 & .53 & $(.89)$ & & & & & & \\
\hline $\begin{array}{l}\text { 2. Turnover } \\
\text { Intentions }\end{array}$ & 2.33 & 1.05 & -.07 & $(.91)$ & & & & & \\
\hline $\begin{array}{l}\text { 3. Affective } \\
\text { Commitmen } \\
\text { t }\end{array}$ & 3.44 & .77 & .08 & $-.63^{\star \star}$ & $(.82)$ & & & & \\
\hline 4. Flextime & 3.08 & 1.82 & -.05 & $.17^{*}$ & $-18^{*}$ & & & & \\
\hline $\begin{array}{l}\text { 5. Com. } \\
\text { Workweek }\end{array}$ & 1.20 & .78 & .07 & .08 & -.02 & .16 & & & \\
\hline 6. Telework & 1.11 & .48 & .11 & -.04 & .07 & $\begin{array}{l}- \\
.19^{*}\end{array}$ & .05 & & \\
\hline $\begin{array}{l}\text { 7. Seg. } \\
\text { Preferences }\end{array}$ & 4.04 & .81 & -.01 & $.17^{*}$ & $-17^{*}$ & $.16^{*}$ & -.01 & -.07 & $(.78)$ \\
\hline $\begin{array}{l}\text { 7. Working } \\
\text { Spouse }\end{array}$ & .53 & & .14 & $-.27^{* \star}$ & $.17^{*}$ & -.05 & -.01 & -.01 & -.04 \\
\hline
\end{tabular}

Figure 3. Histogram of Responses to Segmentation Preferences

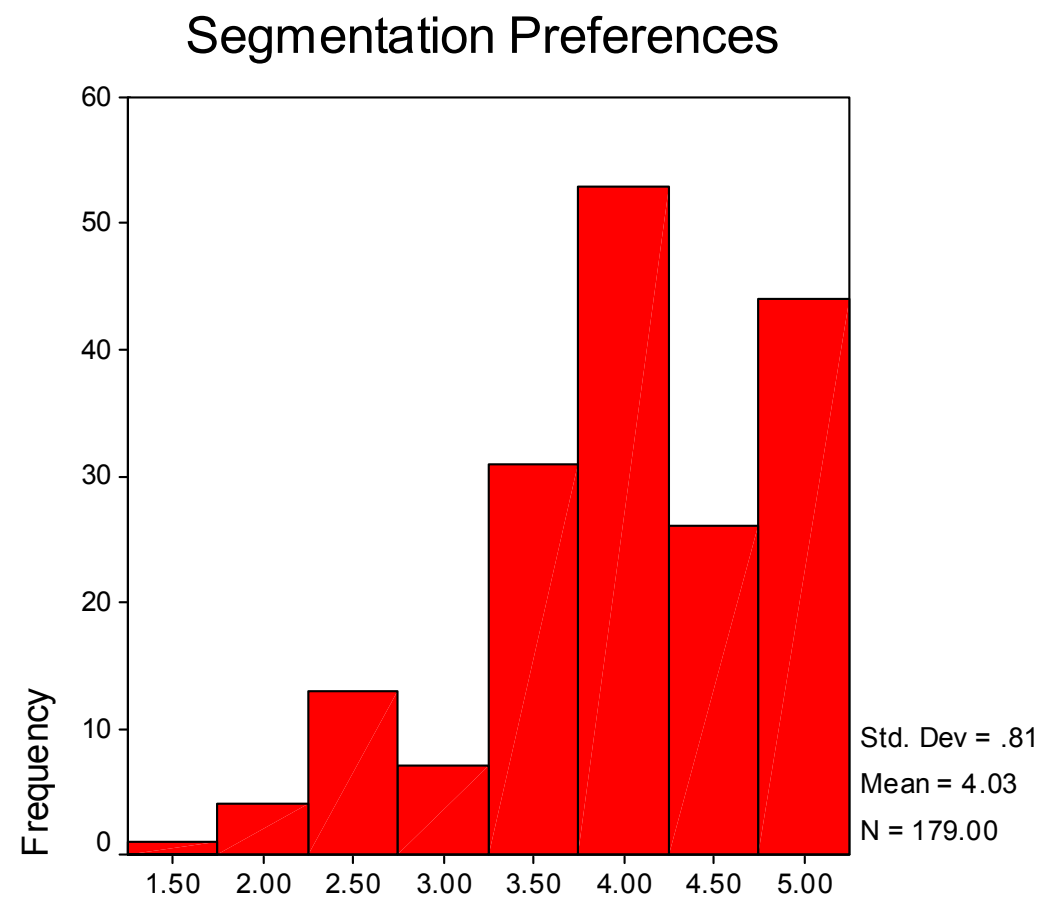


Results of the hypothesis tests are presented in tables 2 through 4 . The first set of hypotheses related to flextime. Hypothesis 1a predicted that for individuals with a high preference for segmentation, individual performance would be higher when the individual uses a high level of flextime. For individuals with a low preference for segmentation (high preference for integration), individual performance was predicted to be lower when the individual uses a high level of flextime. As can be seen in step 3 of Table 2, this hypothesis was not supported. Hypothesis $1 \mathrm{~b}$ predicted that for individuals with a high preference for segmentation, affective organizational commitment would be higher when the individual uses a high level of flextime. For individuals with a low preference for segmentation (high preference for integration), affective organizational commitment would be lower when the individual uses a high level of flextime. As shown in Table 3, there were no significant interactions in this model; therefore, no support was found for hypothesis $1 \mathrm{~b}$. Hypothesis $1 \mathrm{c}$ proposed that for individuals with a high preference for segmentation, turnover intentions would be lower when the individual uses a high level of flextime. For individuals with a low preference for segmentation (high preference for integration), turnover intentions would be higher when the individual uses a high level of flextime. As shown in Table 4, this interaction was not statistically significant, thus no support was found for hypothesis $1 \mathrm{c}$. 
Table 2. Regression Predicting Employee Performance with Segmentation Preferences as a Moderator $(n=156)$

\begin{tabular}{|c|c|c|c|c|c|c|}
\hline & \multicolumn{2}{|c|}{ Step 1} & \multicolumn{2}{|c|}{ Step 2} & \multicolumn{2}{|c|}{ Step 3} \\
\hline & $b(1)$ & $\beta(2)$ & $b(1)$ & $B(2)$ & $b(1)$ & $\beta(2)$ \\
\hline Working Spouse & $\begin{array}{l}.13 \\
(.08)\end{array}$ & .13 & $\begin{array}{l}13 \\
(.08)\end{array}$ & .13 & $\begin{array}{l}.14 \\
(.08)\end{array}$ & .13 \\
\hline Flextime & $\begin{array}{l}-.02 \\
(.02)\end{array}$ & -.06 & $\begin{array}{l}-.02 \\
(.02)\end{array}$ & -.06 & $\begin{array}{l}-.01 \\
(.13)\end{array}$ & -.04 \\
\hline Compressed Work Week & $\begin{array}{l}.05 \\
(.06)\end{array}$ & .07 & $\begin{array}{l}.05 \\
(.06)\end{array}$ & .07 & $\begin{array}{l}-.60 \\
(.35)\end{array}$ & $-.84^{\dagger}$ \\
\hline Telework & $\begin{array}{l}.10 \\
(.08)\end{array}$ & .10 & $\begin{array}{l}.10 \\
(.08)\end{array}$ & .10 & $\begin{array}{l}.00 \\
(.48)\end{array}$ & -.00 \\
\hline Segmentation Preference & & & $\begin{array}{l}.01 \\
(.05)\end{array}$ & .01 & $\begin{array}{l}-.20 \\
(.19)\end{array}$ & -.31 \\
\hline Flextime $\times$ Segmentation Pref. & & & & & $\begin{array}{l}.00 \\
(.03)\end{array}$ & -.01 \\
\hline $\begin{array}{l}\text { Compressed Work Week x } \\
\text { Segmentation Pref. }\end{array}$ & & & & & $\begin{array}{l}.16 \\
(.09)\end{array}$ & $.96^{\dagger}$ \\
\hline Telework x Segmentation Pref & & & & & $\begin{array}{l}.02 \\
(.11)\end{array}$ & .10 \\
\hline Constant & 3.69 & & 3.65 & & 4.50 & \\
\hline $\mathrm{R}^{2}$ & & .04 & & .04 & & .06 \\
\hline Adjusted $\mathrm{R}^{2}$ & & .01 & & .01 & & .01 \\
\hline Change in $\mathrm{R}^{2}$ & & & & .00 & & .02 \\
\hline
\end{tabular}

Notes: Standard errors are in parentheses.

${ }^{\dagger} p<.10,{ }^{*} p<.05,{ }^{* *} p<.01$. 
Table 3. Regression Predicting Affective Organizational Commitment with Segmentation Preferences as a Moderator $(n=159)$

\begin{tabular}{|l|l|l|l|l|l|l|l|}
\hline & Step 1 & \multicolumn{2}{l|}{ Step 2 } & \multicolumn{2}{l|}{ Step 3 } \\
\hline & $b(1)$ & $\beta(2)$ & $b(1)$ & $\mathrm{B}(2)$ & $b(1)$ & $\beta(2)$ \\
\hline Working Spouse & .23 & $.15^{\dagger}$ & .23 & $.12^{\dagger}$ & .24 & $.15^{\dagger}$ \\
& $(.12)$ & & $(.12)$ & & $(.12)$ & \\
\hline Flextime & -.07 & $-.16^{*}$ & -.06 & $.03^{\dagger}$ & .04 & .08 \\
& $(.03)$ & & $(.03)$ & & $(.18)$ & \\
\hline Compressed Work Week & -.01 & -.01 & -.01 & .08 & -.24 & -.23 \\
& $(.08)$ & & $(.08)$ & & $(.51)$ & \\
\hline Telework & .06 & .04 & .05 & .12 & .71 & .46 \\
& $(.12)$ & & $(.12)$ & & $(.69)$ & \\
\hline Segmentation Preference & & & -.16 & $.07^{*}$ & .02 & .02 \\
& & & $(.07)$ & & $(.27)$ & \\
\hline Flextime x Segmentation Pref. & & & & & -.02 & -.25 \\
& & & & & $(.04)$ & \\
\hline Compressed Work Week x & & & & & .06 & .23 \\
Segmentation Pref. & & & & & $(.13)$ & \\
\hline Telework x Segmentation Pref. & & & & & -.16 & -.47 \\
& & & & & $(.16)$ & \\
\hline Constant & 3.47 & & 4.11 & & 3.34 & \\
\hline $\mathrm{R}^{2}$ & & $.06^{\dagger}$ & & $.08^{*}$ & & $.09^{\dagger}$ \\
\hline Adjusted R & & $.03^{\dagger}$ & & $.05^{*}$ & & $.04^{\dagger}$ \\
\hline Change in $\mathrm{R}^{2}$ & & & & $.02^{*}$ & & $.01^{\dagger}$ \\
\hline
\end{tabular}

Notes: Standard errors are in parentheses.

${ }^{\dagger} p<.10,{ }^{*} p<.05,{ }^{* *} p<.01$. 
Table 4. Regression Predicting Turnover Intentions with Segmentation Preferences as a Moderator $(n=157)$

\begin{tabular}{|l|l|l|l|l|l|l|l|}
\hline & Step 1 & \multicolumn{2}{l|}{ Step 2 } & \multicolumn{2}{l|}{ Step 3 } \\
\hline & $b(1)$ & $\beta(2)$ & $b(1)$ & $\mathrm{B}(2)$ & $b(1)$ & $\beta(2)$ \\
\hline Working Spouse & -.52 & - & -.52 & $-.25^{* *}$ & -.53 & $.16^{* *}$ \\
& $(.16)$ & $.26^{* *}$ & $(.16)$ & & $(.16)$ & \\
\hline Flextime & .08 & $.15^{\dagger}$ & .07 & .12 & .11 & .23 \\
& $(.05)$ & & $(.05)$ & & $(.23)$ & \\
\hline Compressed Work Week & .08 & .06 & .09 & .07 & 1.25 & $.65^{\dagger}$ \\
& $(.11)$ & & $(.11)$ & & $(.65)$ & \\
\hline Telework & -.01 &.- .01 & -.01 & -.00 & -.02 & .89 \\
& $(.16)$ & & $(.16)$ & & $(.89)$ & \\
\hline Segmentation Preference & & & .22 & $.17^{*}$ & .56 & .35 \\
& & & $(.10)$ & & $(.35)$ & \\
\hline Flextime x Segmentation Pref. & & & & & -.01 & .06 \\
& & & & & $(.06)$ & \\
\hline Compressed Work Week x & & & & & -.29 & $.16^{\dagger}$ \\
Segmentation Pref. & & & & & $(.16)$ & \\
\hline Telework x Segmentation Pref. & & & & & .01 & .21 \\
& & & & & $(.21)$ & \\
\hline Constant & 2.28 & & 1.42 & & .04 & \\
\hline$R^{2}$ & & $.10^{* *}$ & & $.13^{* *}$ & & $.15^{* *}$ \\
\hline Adjusted R ${ }^{2}$ & & $.08^{* *}$ & & $.10^{* *}$ & & $.10^{* *}$ \\
\hline Change in R $\mathrm{R}^{2}$ & & & & $.03^{* *}$ & & $.02^{* *}$ \\
\hline
\end{tabular}

Notes: Standard errors are in parentheses.

${ }^{\dagger} p<.10,{ }^{*} p<.05,{ }^{* *} p<.01$.

The next set of hypotheses examined the compressed work week. Hypothesis $2 \mathrm{~b}$ proposed that for individuals with a high preference for segmentation, individual performance will be higher when the individual frequently uses a compressed work week, whereas for individuals with a low preference for segmentation, individual performance will be lower when the individual frequently uses a compressed work week. Table 2 shows the results for this hypothesis. There was a marginally significant interaction of segmentation preferences with use of a compressed work week, which suggests preliminary support for this hypothesis. Figure 4 depicts the nature of the interaction, showing that indeed employee performance is highest when a compressed work week is combined with high preferences for segmentation. Likewise, performance decreases for individuals with low segmentation preferences when combined with high use of a compressed work week. Thus, hypothesis 2 a was marginally supported. Hypothesis $2 b$ proposed that for individuals with a high preference for segmentation, affective organizational commitment would be higher when the individual frequently uses a compressed work week, whereas for individuals with a low preference for segmentation, affective organizational commitment would be lower when the individual frequently uses a compressed workweek. Table 3 shows that there was no significant interaction between compressed work week and segmentation preferences. Thus, hypothesis $2 b$ was not supported. Hypothesis $2 c$ proposed that for individuals with a 
high preference for segmentation, turnover intentions would be lower when the individual frequently uses a compressed work week. For individuals with a low preference for segmentation (high preference for integration), turnover intentions will be higher when the individual frequently uses a compressed work week. Table 4 shows that there was a marginally significant interaction in step 3 , which suggests preliminary support for this hypothesis. Figure 4 depicts the nature of the interaction. It shows that for individuals with high segmentation preferences, turnover intentions go down when a compressed work week is used. Likewise, for individuals with low segmentation preferences, turnover intentions increase when a compressed work week is used. This supports hypothesis $2 \mathrm{c}$ at a marginally significant level.

Figure 4.

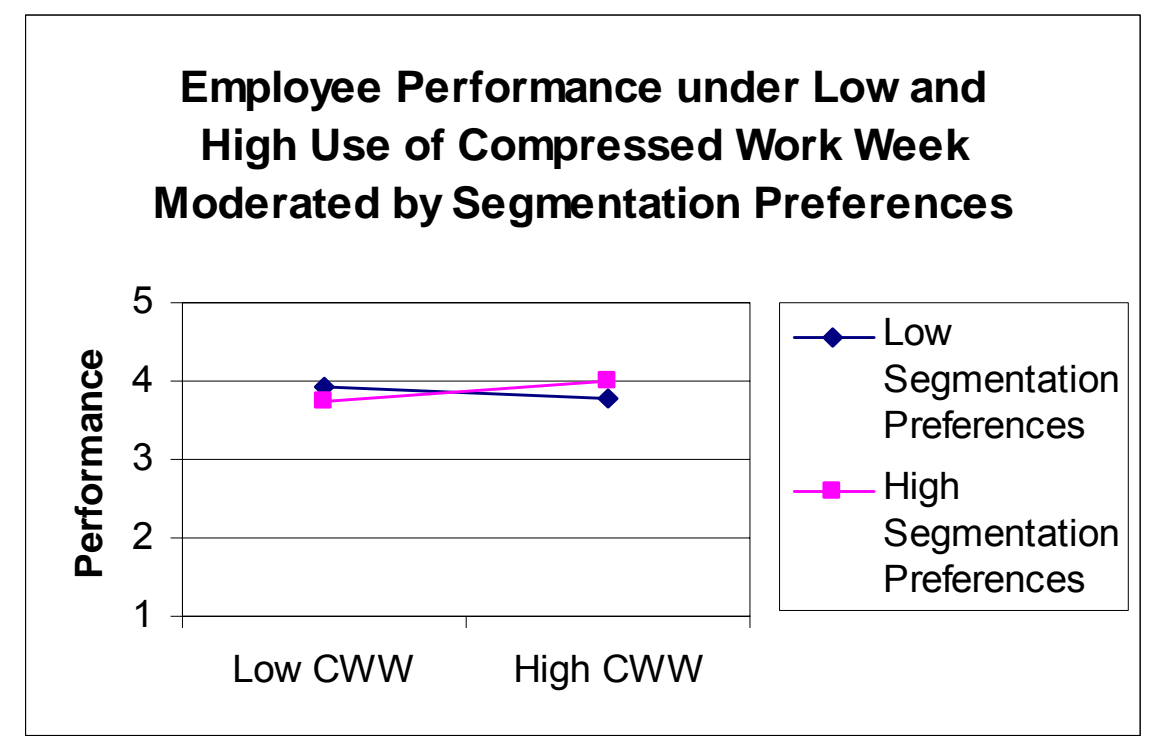

Figure 5.

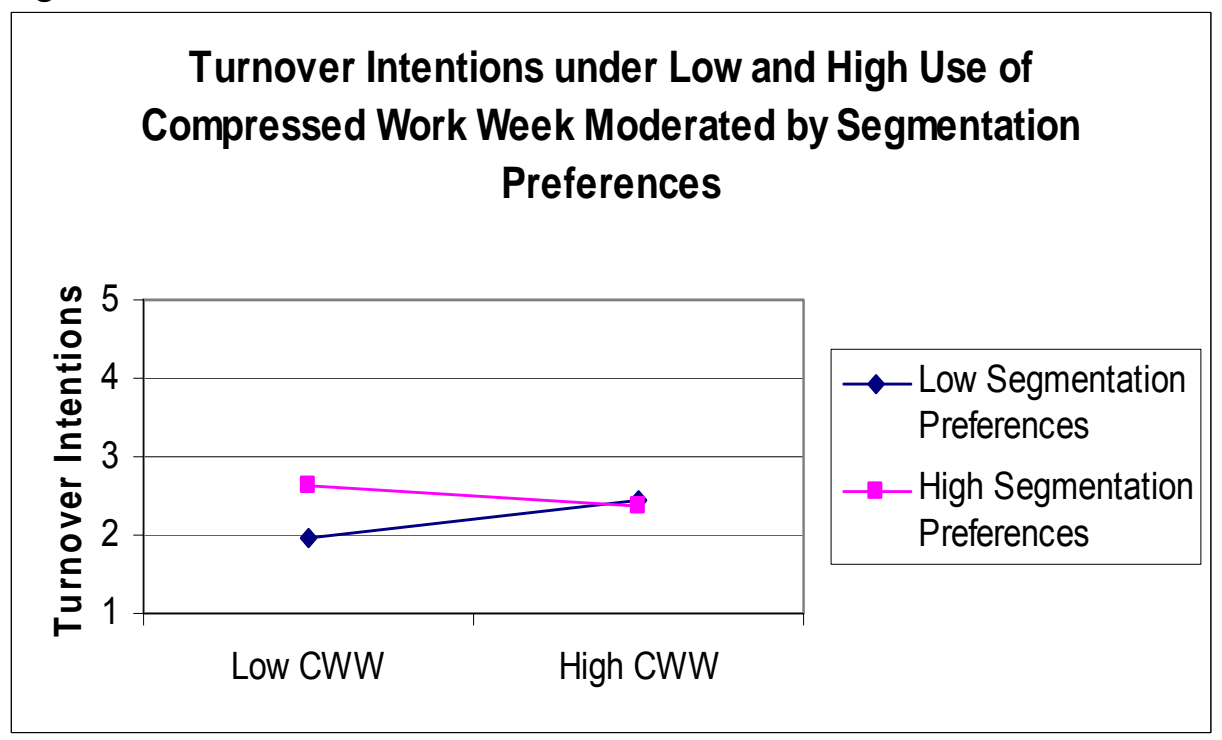


The final set of analyses examined telework. Hypothesis 3a proposed that for individuals with a high preference for segmentation, individual performance would be lower when the individual frequently uses telework. For individuals with a low preference for segmentation, individual performance would be higher when the individual frequently uses telework. Step 3 in Table 2 shows that there was not a significant interaction of telework and segmentation preferences; therefore hypothesis 3a was not supported. Hypothesis $3 \mathrm{~b}$ proposed that for individuals with a high preference for segmentation, affective organizational commitment would be lower when the individual frequently uses telework. For individuals with a low preference for segmentation, affective organizational commitment would be higher when the individual frequently uses telework. Step 3 of Table 3 shows that there was not a significant interaction of telework and affective commitment. Thus, hypothesis $3 \mathrm{~b}$ was not supported. Hypothesis $3 \mathrm{c}$ predicted that for individuals with a high preference for segmentation, turnover intentions would be higher when the individual frequently uses telework. For individuals with a low preference for segmentation, turnover intentions would be lower when the individual frequently uses telework. Step 3 of Table 4 shows that there was not a significant interaction between telework and segmentation preferences. Thus, this hypothesis was not supported.

\section{Discussion}

This study examined the relationship between use of flexible work arrangements and the work-related outcomes of employee performance, affective organizational commitment, and turnover intentions while taking into consideration employees' preferences for segmenting their work life and home life. Boundary theory (Ashforth, et al., 2000; Clark, 2000, Nippert-Eng, 1996) and P-E fit theory (Edwards, 1996) served as a basis for hypothesizing that preferences for segmenting home and work life would interact with individuals' use of flextime, compressed work weeks, and telework to affect employee performance, affective organizational commitment, and turnover intentions. Following the approach advocated by Kreiner (2002), we proposed that a high degree of fit between employee preferences and the type of work arrangement used would result in employees with high affective organizational commitment and performance, as well as low turnover intentions.

Empirical analysis using hierarchical OLS regression did not find support for most of the hypotheses. The only two hypotheses to receive marginal support were hypothesis $2 a$ and 2c, both of which examined compressed work weeks. One possible reason for this lack of findings is that fit between individuals' use of a flexible work arrangement and their preferences for segmenting work and home are not a major contributor to workrelated outcomes such as performance, affective commitment, and turnover intentions. Work and home roles may have "asymmetrically permeable boundaries" (Pleck, 1977: 423), such that the home boundary is more easily disturbed than the work boundary. This suggests that the outcomes most closely related to segmentation preferences and flexible work arrangements may be in the home realm, such as work-family conflict. 
Employees' work lives may not be as affected as much as their home lives by having a good fit between their segmentation preferences and their flexible work arrangements. Another possibility may be the measure of segmentation preferences. The items used were those of Kreiner (2002) in a study of general segmentation preferences and supplies. Given the more specific nature of the flexible work arrangements as a "supply" provided by the organization to enable employees to better segment or integrate their lives, perhaps the measure of preferences also should have focused more specifically on issues directly related to flexible work arrangements. Another potential limitation of this study is the fact that all of the data are self-reported. Although one might have expected self-report bias to falsely inflate the relationship between flexible work arrangements, segmentation preferences, and the various work-related outcomes, this does not seem to be the case, as only two of the hypotheses were marginally supported. Nonetheless, the fact that all of the data came from the employees themselves should be taken into consideration when interpreting the results. Finally, the relatively small sample size and a lack of variance may have limited the ability to detect effects for the variables of interest. The measures for compressed workweek and telework showed that most respondents used such arrangements occasionally or not at all. Wider variance in these measures would increase the power to detect effects.

Organizations have been encouraged by practitioners and academics to foster more integrative workplace policies such as flexible work arrangements (Kreiner, 2002). This research, by illustrating that individuals differ in their preferences to integrate or segment their work and non-work lives, suggests that when considering the implementation of flexible work arrangements, organizations should not assume that all such arrangements will be attractive and effective for all employees. With the exception of compressed workweeks, this study did not find that a match in work arrangement and preference for segmentation affected work-related outcomes. Given the previously mentioned limitations to this study, further research is recommended to determine whether the fit of an employee with his or her work arrangement should be taken into account by an organization for performance purposes.

\section{References}

Apgar IV, M. (1998). The alternative workplace: Changing where and how people work. Harvard Business Review, 76, 121-136.

Ashforth, B.E., Kreiner, G.E., \& Fugate, M. (2000). All in a day's work: Boundaries and micro role transitions. Academy of Management Review, 25, 472-491.

Catalyst. (1997). A new approach to flexibility: Managing the work/time equation. New York: Catalyst.

Di Martino, V. \& Wirth, L. (1990). Telework: A new way of working and living. International Labour Review, 129, 529-554. 
Duxbury, L., \& Haines, G. (1991). Predicting alternative work arrangements from salient attitudes: A study of decision makers in the public sector. Journal of Business Research, 23, 83-97.

Edwards, J. R. (1996). An examination of competing versions of the person-environment fit approach to stress. Academy of Management Journal, 39, 292-339.

Friedman, D. E. (1990). Work and Family: The New Strategic Plan. Human Resource Planning, 13, 79-89.

Golembiewski, R. T., \& Proehl, C. W. (1978). A survey of the empirical literature on flexible work hours: Characters and consequences of a major innovation. Academy of Management Review, 3, 837-853.

Hicks, W., \& Klimoski, R. J. (1981). The impact of flextime on employee attitudes. Academy of Management Journal, 24, 333-341.

Hill, E. J., Miller, B. C., Weiner, S. P., \& Colihan, J. (1998). Influences of the virtual office on aspects of work and work/life balance. Personnel Psychology, 51, 667-683.

Kreiner, G. (2002). Boundary preferences and work-family conflict: A personenvironment fit perspective. Paper presented at the 2002 Academy of Management annual meeting, Denver, Colorado.

Kropf, M. B. (1996). From policy to practice. HRMagazine, 41, 4, 88-92.

Latack, J. C. \& Foster, L. W. (1985). Implementation of compressed work schedules: Participation and job redesign as critical factors for employee acceptance. Personnel Psychology, 38, 75-92.

Morgan, H., \& Milliken, F. J. (1992). Keys to action: Understanding differences in organizations' responsiveness to work-and-family issues. Human Resource Management. 31, 227-248.

Nippert-Eng, C. E. (1996). Home and work: Negotiating boundaries through everyday life. Chicago: University of Chicago Press.

Olmsted, B. \& Smith, S. (1997). Managing in a flexible workplace. New York: Amacom.

Pierce, J. L., \& Dunham, R. B. (1992). The 12-hour work day: A 48-hour, eight-day week. Academy of Management Journal. 35, 1086-1098.

Pierce, J. L., Newstrom, J. W., Dunham, R. B., \& Barber, A. E. (1989). Alternative Work Schedules. Needham Heights, MA: Allyn and Bacon, Inc.

Pleck, J. H. 1977. The work-family role system. Social Problems, 24, 417-427. 
Pitt-Catsouphes, M. \& Marchetta, A. (1991). A coming of age: Telework. Boston: Boston University, Center on Work and Family.

Ramsower, R. M. (1985). Telecommuting: The organizational and behavioral effects of working at home. Ann Arbor: UMI Research Press.

Rau, B. L. \& Hyland, M. M. (2002). Role conflict and flexible work arrangements: The effects on applicant attraction, Personnel Psychology, 55, 111-136.

Ronen, S. (1981). Flexible working hours: An innovation in the quality of work life. New York: McGraw-Hill.

Ronen, S. (1984). Alternative work schedules: Selecting, implementing, and evaluating. Homewood, IL: D. Jones-Irwin.

Ronen, S. \& Primps, S. B. (1981). The compressed work week as organizational change: Behavioral and attitudinal outcomes. Academy of Management Journal, 6, 6174.

Scandura, T. A., \& Lankau, M. J. (1997). Relationships of gender, family responsibility and flexible work hours to organizational commitment and job satisfaction, Journal of Organizational Behavior, 18, 377-391.

Schein, V. E., Maurer, E. H., \& Novak, J. F. (1977). Impact of flexible working hours on productivity. Journal of Applied Psychology, 62, 463-465.

Tomaskovic-Devey, D., \& Risman, B. J. (1993). Telecommuting innovation and organization: A contingency theory of labor process change. Social Science Quarterly, 74, 367-385.

Vega, A. \& Gilbert, M. J. (1997). Longer days, shorter weeks: Compressed work weeks in policing. Public Personnel Management, 26, 391-402.

Wayne, S. J., Shore, L. M., \& Liden, R. C. (1997). Perceived organizational support and leader-member exchange: A social exchange perspective. Academy of Management Journal, 40, 82-111. 